while taking the drug she was violent and aggressive yet without it was "a happy go lucky person," which begged the question (unasked in the programme) why she was taking it in the first place.

But then in every case the patient's story was presented straight with no attempt to explain the sort of equivocation and rationalisation that can occur when depressed patients seek to evaluate their symptoms. Like many observers before them the programme makers accepted that people were acting irrationally when they tried to commit suicide but implied that the same people were quite rational when they talked about anything else.

If you set up your stall, as Leonard Finz and the scientologists have done, and invite people to contact you if they have had violent thoughts of self destruction while taking a drug as widely used as fluoxetine you are bound to get a response, even without the incentive of potentially rewarding litigation. Just as I suspect that if you set out to track down people who had similar thoughts while not taking fluoxetine you could muster even more impressive numbers. That's why one of the first lessons most people learn from clinical experience is the danger of anecdotal evidence.

Yet anecdotage is the fuel of journalism for an audience responds more readily to personal stories than to a prosaic statement of general principle. We hacks discover early in our careers that we need to get the human interest into the first paragraph or into the first sequence to appear on the screen. And there's no harm in using anecdotal evidence to sustain a story that has been rigorously tested-or, in the jargon of our trade, made to "stand up"-in editorial judgments that take place off stage. The technique is used regularly in the best of the BBC's Horizon series and Channel Four's Equinox.
Dispatches is not, of course, a science series but an unashamedly polemical one. Indeed, that's one of its attractions, especially to those of us who believe that journalism's most socially useful function is to keep authority on the defensive. In this programme, however, I thought that the polemics failed because too much emotional weight was put behind too thin a story. Leonard Finz who addresses everybody, including television interviewers, as if they were a jury, is a compelling advocate. Yet even the most compliant of jurors likes to hear occasionally from a counsel for the defence.

Patients taking fluoxetine will have been attracted to the programme by its title. General practitioners and psychiatrists will soon discover whether any of them were frightened off what can be a life saving drug. - MICHAEL O'DONNELL, author and broadcaster

\section{A tragic and wicked waste of life}

\section{Elizabeth Ward}

$\mathrm{I}$ is more than 25 long years since my son, then aged 13, went into renal failure and during that time I have been witness to many changes in the treatment of patients with failing kidneys. In those far off days when dialysis facilities were few and far between mishandled drug treatment and dietary restrictions were the order of the day. "By malnutrition" could have been as reasonably recorded on the death certificate as the cause of death as "end stage renal failure." As more renal units were opened and the renal replacement programme was enlarged more patients were offered the benefit of haemodialysis and more doctors specialised in renal medicine. By the beginning of the 1970s there were some 1200 patients in Britain on haemodialysis ranging in age between 17 and 50. Renal transplantation was in its infancy, however, and in those early days many a patient was lost with a good functioning graft having been killed by huge doses of immunosuppressive drugs-whose horrendous side effects were only just beginning to be measured.

By the end of the 1970s, however, renal transplantation had become a routine treatment for patients destined otherwise to be unfortunate enough to spend their remaining years on thrice weekly dialysis. The surgical procedure had become straightforward, the immunosuppressives more refined, and the body's reaction to them better understood. The great remaining problem was a serious shortage of cadaveric kidneys. Ten years on little has changed-except the number of patients awaiting transplantation, which has quadrupled. Each year the British Kidney Patient Association commissions a Gallup survey of public attitudes. The most recent survey showed that while three quarters of the adult population of Britain are willing for their kidneys to be used for transplant purposes after death, still no more than $7 \%$ carry a donor card recording their wishes. Most

\section{... legislation will never see the light of day without the backing of the medical profession.}

people are sympathetic up to a point to the plight of Britain's kidney patients and would, I believe, genuinely like to think that all those who required life giving transplants could receive them, but there are substantial obstacles.

People who have decided that their kidneys may be used after their death have only one way in which they can record their wishesthey can carry a donor card. But a donor card is not a legal document and the next of kin can override the wishes of the dying patient. Hospital doctors themselves seem to have decided that niceties require that an approach for permission to remove the kidneys should be made to the patient's relatives at the time of optimum grief-and not unnaturally this approach is often shirked. For those surprisingly few doctors who can actually see in their dying patients the chance of life for patients of their colleagues their brave approach is all too often met with a rebuff. It cannot be right that the hospital doctor should feel it necessary to approach the relative at such a traumatic time and make what would seem to be an unbearably in- sensitive request. Neither can it be fair for the relatives who may have refused permission for their loved one's organs to be used for transplantation to be faced later with feelings of guilt and shame that they denied the chance of life to other people. After many years of discussion and argument with patients, doctors, and ethicists, I believe that we should be willing to assume that the viable organs of those whose name does not appear on a dissent register can be used in life saving operations: in other words an "opting out" system. Of course I accept that adequate facilities would need to be made to record the dissent of those unwilling to save the lives of others after their own demise.

But I am a realist and I am well aware that opting out legislation will never see the light of day without the backing of the medical profession. Yet surely once most doctors in Britain cast aside their professional attitudes for long enough to be able to see themselves or their relatives as potential organ recipients they would give that support? Surely doctors more than anyone else should understand that no cadaveric kidney should be lost to the transplant surgeons desperately trying to save the lives of their patients?

The introduction of seat belt legislation into Britain some few years ago amazed a great number of people who claimed that the law severely interfered with the rights of the individual. The bill went through parliament with ease because it had the full support of the entire medical profession. Until the medical profession is prepared to give similar support to opting out legislation as being the only possible solution to the grave shortage of donor organs for transplantation there will be a continuing waste of life - a waste which I believe to be wicked as well as tragic.

Elizabeth Ward is president of the British Kidney Patient Association 